Occultations of Stars by the Moon (visible at Greenwich)

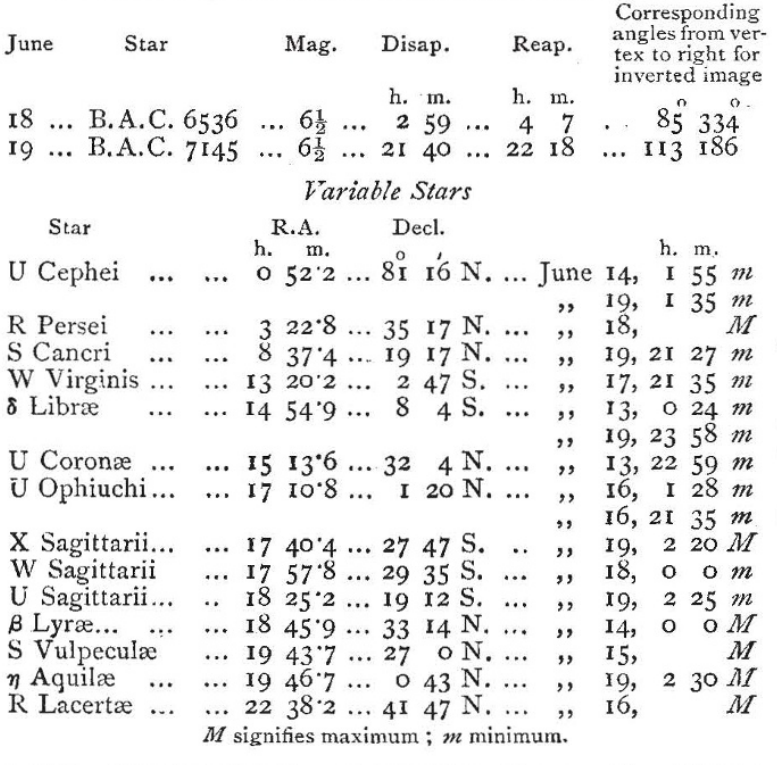

\section{BIOLOGICAL NOTES}

DEVElopment OF OPHIOPHOLIS AND ECHINARACHNIUS.In the last series of studies from the Newport Marine Zoological Laboratory we find a memoir by Mr. Walter Fewkes, on the development of an Ophiuroid (Ophiopholis aculeata, Gray) and of an Elypeastroid (Echinarachnius parma, Gray). But few observations have been published on the metamorphosis of Ophiopholis, and these often misleading. The eggs would appear to be extruded separately into the water, and the young pass through a metamorphosis in which a plutens-larva is formed; the development of this pluteus is different from that of any described Ophiuran, though allied to that in Ophiothrix. The ova were voluntarily shed by the female on August 17 ; they were fertilised outside the body, and appeared to be very hardy. The yolk has a central and a peripheral region, which are distinguishable in the eight-cell and previous stages of segmentation. The cleavage is like that of other Echinoderms. A gastrula is formed by the invagination of the blastoderm, and consequently the stomach of the pluteus is an infolded wall of the blastoderm, and not formed by delamination from the cells in the cavity. The mesoderm-cells originate in two lateral clusters. The oldest pluteus observed was a little more than three days old; they, however, appeared to be easily raised, and it is to be hoped that they will be yet traced to an adult form. In Echinarachnius the sexes are distinct, and in some cases there were colour-distinctions. In the experiments on the ovum of $E$. parma, artificial fertilisation was resorted to from the middle of July to the end of August; it was easily effected. In its mode of segmentation it resembles that of other Echinoderms. It has no polar globules, but possibly these may be formed while the egg is in the ovary. As in some other Echinoderms, a gastrula is formed by invagination. The pluteus figured by A. Agassiz in the revision of the Echini as probably that of Echinarachnius proves to belong to this species at about a week old. The development of the young Echinarachnius on the water-tube of the pluteus resembles that of other sea-urchins. The rosette-form of the water-tubes described in other Echinoderms also occurs. The first-formed calcareous deposits of the test are trifid in form, and vary in number in different specimens. The extremity of each trifid division bifurcates later in its growth, and the calcareous body thus formed appears to be inclosed in a transparent wall, which has a spherical outline. Spines are very early formed, and are proportionately very large as compared with those of the adult. The various stages are illustrated in numerous figures on eight, in several cases folding, plates.-Bull. Mus. Comp. Anat. Harvard College, vol. xii. No. 4, March 1886.

The LeEches of JAPAN.-In the April number of the

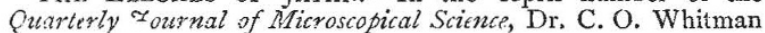

publishes the first hundred pages of a memoir on the leeches of Japan. The material for the study was collected while the author was connected with the University of Tokio (I879-8I). The coloured drawings accompanying the memoir were executed by Mr. Nomura, a young Japanese artist, and they well deserve the remarks $n^{f}$ 'he author: "Mr. Nomura's attention to the minutest detals, his infinite patience, trained eye, and his remarkably skilful brush, have given results that are marvels for neatness and accuracy." The first part of this study treats of the land leech (Hamadipsa japonica), the medicinal leech (Hirudo medicinalis), and of three species of toothless leeches, which form a new genus, Leptostoma. It also contains a comparison of a few species from Europe, Asia, and America, and a considerable portion is devoted to a comparative study of the different genera, in the endeavour to find a satisfactory basis of classification. This has in a great measure been found in a law of abbreviation of the somites, which, in addition, gives a key to the phylogeny of the genera. The land leech is shown to be a highly instructive and specialised form. The genus Hirudo has been re diagnosed (p. 364), and while internal structure has been dealt with to only a very limited extent, still some interesting facts in connection with the nephridial organs of the land leech are detailed, and the existence of from twelve to fourteen senseorgans on the first ring of each complete somite is demonstrated, and they-are homologued with the eyes, having possibly also other sense-functions. The author reserves the genus Hæmadipsa for the land leeches of Ceylon, India, and Japan, with three jaws and five inter-genitalia rings. $\mathrm{He}$ ascribes the genus to Tennant, but may it not have been formed by Baird? $H$. japonica is confined to the mountain slopes and ravines, never descending into the plains. It is not only a mountain leech, but it keeps habitually to the ground, living in moss, or under damp leaves and rubbish. They are most voracious, and on the approach of man or beast are at once on the alert. They advance by rapid strides. They bite so gently as scarcely to attract attention, but the wound is deep, and the scar is more or less permanent. They gorge on for about 30 to 40 minutes, and then drop; while sucking they become bedewed with a transparent liquid, which keeps them moist. If placed in water, they do not swim but sink, and then creep out; and while havingra decided preference for a terrestrial life, can support life for days in water. If into a jar of hungry leeches a puff of breath is blown, they become immensely excited, and it will be difficult to keep them in ; while trying to keep back one, a dozen others will rush out. In a most interesting series of paragraphs Dr. Whitman traces the intimate relation that exi-ts between these land and the medicinal leeches, the latter essentially fresh-water forms. The geographical area of land-leeches is mainly within the tropics, though in Japan they are exposed to a wide range of temperature. H. nipponia is described as a new Japanese medicinal leech, well known to the Japanese, and with habits and mode of life just like our European leech. Leptostoma, a new genus, is established (p. 376) on three species of almost edentulous leeches, which, though having a common ancestry with Hirudo, were not derived from it. All three species, L. acranulatum, L. edentulum, and L. pigrum, are from Tokio, and are fully diagnosed and beautifully figured. The segmental organs are shown to be sense-organs, and that from them the eyes have developed, so that they may be regarded as incipient eye spots.

New Element of the Blood and its Relation to Coagulation. - In an important paper by Mr. Geo. T. Kemp on this subject, he comes to the conclusion that in addition to the red corpuscles and leucocytes the blood normally contains a third histological element-the "plaques." These have been variously considered as young red corpuscles; as nuclei floating in the blood; as being derived from the red or the white corpuscles; as being fibrin ; and as being globular depositions pro duced by cooling of the blood; but the author proves that, although strong resemblances exist between the plaques and other histological elements of the blood, there is not yet sufficient evidence to establish a genetic connection. The plaques should thcrefore, at least for the present, be regarded as independent elements. When the blood is drawn, the plaques break down almost immediately, and this is not true of any other element of the blood. This breaking down of the plaques seems intimately connected, in its time relations at least, with the clotting of the blood. If a good-sized drop of blood from a finger be let fail on a cover-glass, and as quickly as possible washed by a good jet of 75 per cent. $\mathrm{NaCl}$ solution, and then examined under the 
microscope, the plaques, which have a property of sticking to the glass slip, will be found to fill the field; some will be isolated, some will be in groups; they will now appear glistening and granular, and their contours are jagged, becoming more and more so as time elapses; finally only a granular mass will be fund. If, however, a drop of osmic acid be placed on the finger before the drop of blood be drawn, all the elements will be found presenting their normal appearances, and the plaques will be seen as pale homogeneous structures varying greatly in size, but for the most part about one-third or one-fourth of the diameter of the red corpuscles; they are biconcave, but not as much so as the red corpuscles. Once thus hardened they never change their form, but the plaques first referred to will be found to alter their form very speedily, and pari passu with these changes, processes are seen which run out from the granular masses, and when coagulation sets in these processes are nearly always found to be continuous with threads of fibrin. The connection between the breaking down of the blood is not histological but chemical. The plaques appear to give up a soluble substance which is active in coagulation. This active agent is most probably a fibrin ferment. Fibrin is deposited histologically independent of any of the cellular elements of the blood and when the clot is very scant. The fibrin is seen deposited as long, needle-shaped, crystal-like bodies. - Studies from Biolog. Lab., Fohns Hopkins Univ., vol. iii. No. 6, May I886,

\section{ON RECENT PROGRESS IN THE COAL-TAR INDUSTR $Y^{1}$}

\section{II.}

A ZO-COLOURS.-Amongst the most important of the artificial colouring matters may be classed the so-called azocolours. These colours are chiefly bright scarlets, oranges, reds, and yellows, with a few blues and violets. They owe their existence to the discovery by Griess, in $\mathbf{1} 860$, of the fact that the so-called azo-group $-\mathrm{N}=\mathrm{N}$ - can replace hydrogen in phenols and amido-compounds. But it is to Dr. O. N. Witt that is due the honour of having given the first start in a practical direction to the chrysoidine class of azo-colours by the discovery of chrysoidine, and perhaps still more so by the suggestions contained in a paper read before the Chemical Society. Dr. Caro, of Mannneim, was also acquainted with several compounds which belong to this class at the time Witt published his results, but it does not appear that he made practical use of them until Witt introduced the chrysoidines and tropeolines. To Roussin, of the firm of Poirrier of Paris, is due the credit of having first brought into the market some of the beautiful azo-derivatives of naphthol. Griess, therefore, as the original discoverer of the typical compounds and reactions by which the azo-colours are obtained, may be considered as the grandfather, whilst Roussin and Witt are really the fathers, of the azo-colour industry. Nor must it be forgotten that it is to Perkin we owe the recognition of the value of the sulpho group in relation to azo-colours, a discovery patented in 1863. Moreover it is interesting to note that changes in colour from yellow to red and claret are effected by the increase in the molecular weights of the radicals introduced an well as by the relative positions occupied by these groups.

Indophenol.-Witt is also the discover of a new blue dye-stuff termed indophenol, which has been used as a substitute for indigo. Certain difficulties, however, have arisen in the adoption of this colour on the large scale. The most important use indophenol is at present put to is for producing dark blues on reds dyed with azo-colours, both on wool and cotton. The piece goods are dyed a uniform red first, and then printed with indophenol white; for like indigo itself indophenol yields a colourless body on reduction, and this being a very powerful reducing agent destroys the azo-colour, being itself transformed into indophenol blue. The process works with surprising nicety and is very cheap. The blue is formed and the red discharged with such precision that patterns can be produced in which the blue discharge covers a great deal more space than the original red. This new printing process was devised by Mr. H. Koechlin, of Lorrach. The reds used for the purpose are in the case of wool the usual azo-scarlets, for cotton Congo red.

Artificial Indigo.- A bout five years ago the speaker had the

I A Discourse by Prof. Sir Henry E. Roscoe, M P., LL.D., F.R.S., delivered at the Royal Institution, Friday, April 16. I886. Continued from
p. in4. honour of bringing before this audience ${ }^{1}$ the remarkable discovery made by Baeyer of the artificial production from coal-tar products of indigo blue. Since that time but little progress has been made in this manufacture, as the cost of the process, unlike the case of alizarin, has as yet proved too serious to enable the artificial to compete successfully in the market with the natural indigo.

Through the kindness of a number of eminent colour manufacturers in this country and on the Continent, the speaker was enabled to illustrate his subject by a most complete series of specimens both of the colours themselves and of their application to the dyeing and printing of fabrics of all kinds. His thanks are especially due to his friend, Mr. Ivan Levinstein, of Manchester, for the interesting series of samples of cloth dyed with known quantities of fifty different coal-tar colours, each having a different chemical composition; also to the same gentleman, and to Messrs. Burt, Boulton, and Haywood, of London, for the interesting and unique series of specimens indicating the absolute quantities of products obtainable from one ton of coal, as well as for much assistance on the part of Mr. Levinstein in the preparatinn of the experimental illustrations for this discourse. To Dr. Martius of Berlin for a valuable series of colours, especially the well-known Congo red, made by his firm, including samples of wool dyed therewith, he is also much indebted. For the interesting details concerning indophenol and its applications the speaker owes his thanks to Dr. Witt and M. Koechlin.

Coal-'ar Antipyretic Medicines. - Next in importance to the colour industry comes the still more novel discovery of the synthetical production of antipyretic medicines.

Up to this time quinine has held undisputed sway as a febrifuge and antiperiodic, but the artificial production of this substance has as yet eluded the grasp of the chemist. Three coal-tar products have, however, been recently prepared which have been found to possess strong febrifuge qualities, which if still in some respects inferior to the natural alkaloids, yet possess most valuable qualities, and are now manufactured in Germany at Höchst and at Ludwigshafen in large quantity. And here it is well to call to mind that the first tar colouring-matter discovered by Perkin (mauve) was obtained in 1856 during the prosecution of a research which had for its object the artificial production of quinine.

In considering the historical development of this portion of his subject, the speaker added that it is interesting to remember that the initiative in the production of artificial febrifuges was given by Prof. Dewar's discovery in I88I that quinoline, the basis of these antipyretic medicines, is an aromatic compound, as from it he obtained aniline. Moreover that Dewar and McKendrick were the first to observe that certain pyridine salts act as febrifuges. So that these gentlemen may be said to be the fathers of the antipyretic medicines, as Witt and Roussin are of the azo-colour industry.

Kairine, the first of these, was discovered by Prof. O. Fischer, of Munich, in the year $188 \mathrm{I}$, whilst engaged on his investigations of the oxyquinolines. The febrifuge properties of this substance were first noticed by Prof. Filehne, of Erlangen. Kairine is manufactured from quinoline, a basic product derived from aniline by heating it with glycerin and nitrobenzene by the following process. When treated with sulphuric acid, $\mathrm{SO}_{4} \mathrm{H}_{2}$, it forms quinoline sulphonic acid, and this when fused with caustic soda yields axyquinoline, which is then reduced by tin and hydrochloric acid into tetrahydroxyquinoline, and this again on treatment with $\mathrm{C}_{2} \mathrm{H}_{5} \mathrm{Br}$ yields ethyl-tetraoxyquinoline or kairine. The lowering of the temperature of the body by this compound is most remarkable, though, unfortunately, the action is of much shorter duration than that effected by quinine itself; but on the other hand, with the exception of its burning taste, it exerts no evil effects such as are often observed after administration of large doses of quinine. The commercial article is the hydrochloride, the price is $85 s$. per lb., and the quantity manufactured has lately diminished owing to the discovery of the second artificial febrifuge, antipyrine.

The following graphical formula shows the constitution of kairine :-

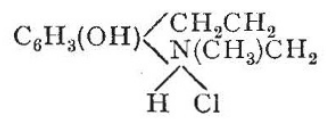
$188 \mathrm{r}$ 